\title{
Platelet Rich Fibrin -A Second Regeneration Platelet Concentrate and Advances in PRF
}

\author{
Pavan Kumar $A^{1}$, Vikram Reddy $\mathrm{G}^{2}$, Raja Babu $\mathrm{P}^{3}$, J agadish Reddy $\mathrm{G}^{4}$
}

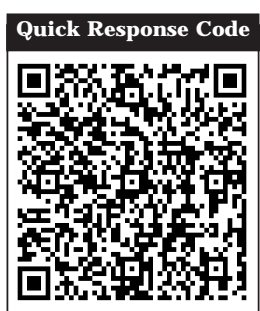

doi: $10.5866 / 2015.7 .10251$

1Post Graduate student

${ }^{2}$ Reader

${ }^{3}$ HOD \& Professor

${ }^{4}$ Reader

Department of Periodontics,

Kamineni Institute of Dental Sciences,

Narketpally, Nalgonda, Telangana.

\section{Article Info:}

Received: October 11, 2015

Review Completed: November 10, 2015

Accepted: December 8, 2015

Available Online: March, 2016 (www.nacd.in)

(C) NAD, 2015 - All rights reserved

Email for correspondence:

pavankumar2524@gmail.com

\section{INTRODUCTION:}

Regeneration requires an orchestrated sequence of biologic events, such as cell migration, adherence, growth, and differentiation, to have the potential to increase the success and predictability of regenerative procedures. Platel ets play a crucial role in hemostasis and wound healing. The á-granules of platelets release platelet-derived growth factor (PDGF), transforming growth factor (TGFb), and insulin-likegrowth factor (IGF-I). During activation, á granules fuses with platelet cell membrane releases growth factors. These growth factors bind to transmembrane receptors of target cells (Osteoblasts, fibroblasts, endothelial cells, and

\begin{abstract}
:
Regeneration is reconstitution of both hard and soft tissues in structure and function. Various modalities for regenerating of the tissues induding bone grafts and substitutes, guided tissue regeneration (GTR) and the application of polypeptide growth factors (PGFs) to the surgical wound to promote periodontal regeneration. Autologus blood preparations are richest source for these polypeptide growth factors. Fibrin sealants act like as last step in the coagulation casacade.PRP is the first generation platel et concentrate. But the disadvantages of PRP are using of bovine thrombin which leads to allergic reaction. Choukron pioneered the Platelet rich fibrin (PRF).The present review highlights the preparation, advantages, limitations and various advances in PRF.
\end{abstract}

Key words: Growth factors, Platelet rich plasma, Platelet rich fibrin 
A physiological enriched fibrin complex matrix (PRF) releases growth factors in a controlled manner for longtime when compared to fibrin glue enriched with cytokines.

The preparation of PRF is very simple. A blood sample is taken without anticoagulant in $10 \mathrm{ml}$ tube then centrifuged in a table centrifuge at $2700 \mathrm{rpm}$ for 12 mins. I $n$ the absence of anticoagulant, platel et activation and fibrin polymerization are triggered in a natural manner immediately. ${ }^{4}$ Fibrinogen is at first concentrated in the upper part of thetube, until the effect of the circulating thrombin transforms it into a fibrin network. The result is a fibrin clot containing the platel ets located in the middle of the tube, just between the red blood cell layer at the bottom and acellular plasma at the top (F igure 1a). If the duration required to collect blood and launch centrifugation is overly long, failure will occur. The fibrin will polymerize in a diffuse way in the tube and only a small blood clot without consistency will be obtained. ${ }^{4}$

It contains cytokines such as IL-1, -4, -6, and growth factors such as Transforming Growth F actor beta 1 (TGF-âl), Platelet Derived Growth Factor (PDGF), and Vascular Endothelial Growth Factor (VEGF ). ${ }^{5}$ The combination of fibrins and cytokines within PRF becomes a powerful scaffold with an integrated reservoir of growth factors for tissue regeneration. The fibrin matrix in PRF acts as natural guide for angiogenesis, natural support to immunity and guides the coverage of wounds (Figure1b). 4

\section{CLINICAL IMPLICATIONS OF PRF: ${ }^{3-5}$}

1. In sinus lift procedures

2. Socket preservations

3. Intrabony defects with or without bone grafts (Figure 1c)

4. PRF membrane has been used for gingival recession coverage with coronally advanced or lateral pedicle flap for multiple and single recession respectively

5. Endo perio lesions/F urcation defects

\section{ADVANTAGES OF PRF OVER PRP: 3}

1. No need of addition of bovine thrombin or other anticoagulants so it is completely safe.

2. Standard production protocol.

\section{LIMITATIONS OF PRF: ${ }^{5}$}

1. As it is produced from autologus blood in limited quantities, limits the systemic utilization in general surgery or extensive surgical procedures.

2. PRF tissue banks are unfeasible. The fibrin matrix contains all the circulating immune cells and all the highly antigenic plasmatic molecules. That is why PRF membranes are totally specific to the donor and cannot constitute an allogenic graft tissue

\section{TITANIUM-PREPARED PLATELET-RICH FIBRIN (T-PRF):}

Some authors are worried about glassevacuated blood collection tubes with silica particles as these particles may cause health hazards. ${ }^{5}$ Only small fraction of these silica particles are sediment ting with red blood cells. Majority of silica particles suspends in a buffy coat so that these particles reach to patient when these product is used for treatment. ${ }^{6}$ Although this is not practically concluded (the architecture of L-PRF change with type of material used for its preparation), some of the authors used more biocompatible material titanium for PRF preparation (F igure 2). ${ }^{7}$ Although basic histological structure similar between T-PRF and L-PRF, there is some difference in fibrin structure in T-PRF. The fibrin of T-PRF is more woven and thicker when compare with L-PRF. The difference may be due to the biocompatibility and hemocompatibility of titanium, which led to the formation of a more polymerized fibrin (Figure $3 \boldsymbol{\&} 4$ ). ${ }^{8}$ M ore research is required on T-PRF in terms of absorption time in body and clinical advantage over L-PRF.

ADVANCED PRF (A-PRF): The centrifugation protocol of A-PRF is $1500 \mathrm{rpm} 14$ mins, Differ from Standard PRF Which is $2700 \mathrm{rpm}$ 12 mins.

\section{RATIONALE BEHIND INVENTION OF A-PRF :}

1. Monocytes releases higher concentration of growth factors.

2. Decreases centrifugation rpm and increased time gave enhanced neutrophil granulocytes in the distal part ( yellow color) of the clot

3. Neutrophil granulocytes increases differentiation of monocytes

PRF clots formed with A-PRF centrifugation protocol showed a loose structure with more interfibrous space, and more cells in distal part of fibrin clot (Figure 5). The distribution of cells is even in A-PRF clot. More research is required on A- 


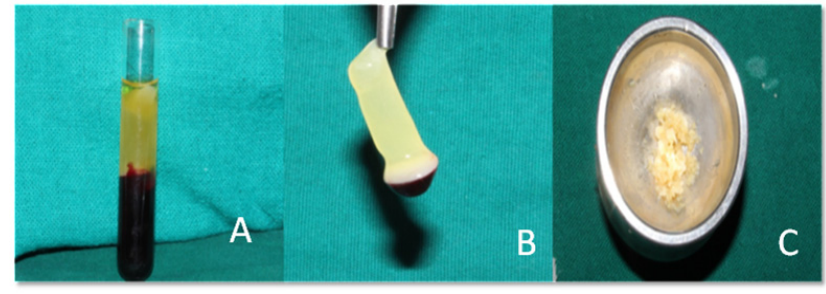

Figure 1: a) Platelet -rich fibrin in test tube; b) Platelet-rich fibrin; c) PRF mixed with bone graft.

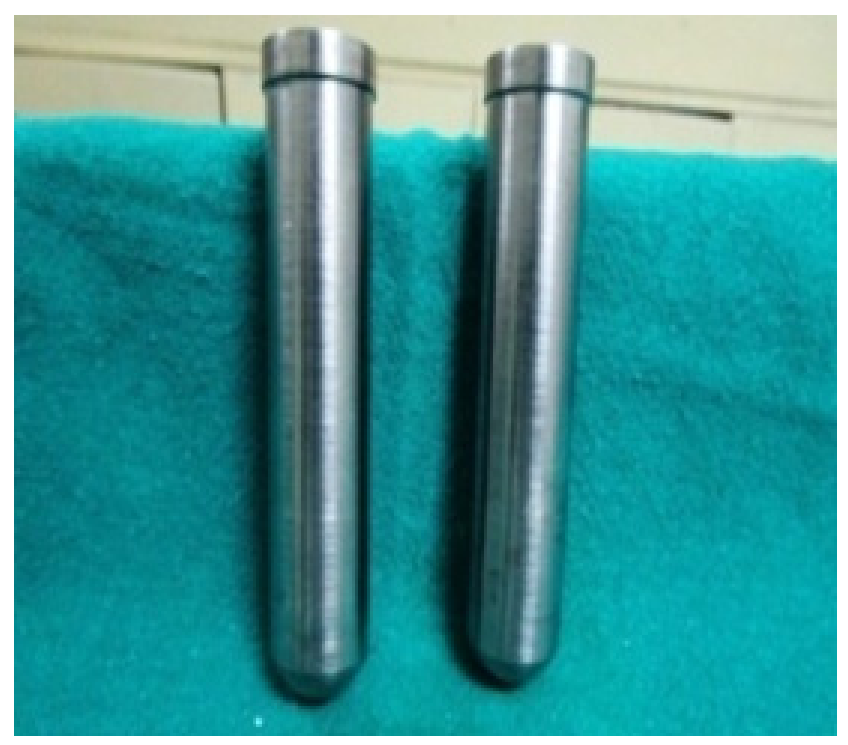

Figure 2: Titanium test tubes for T-PRF preparation

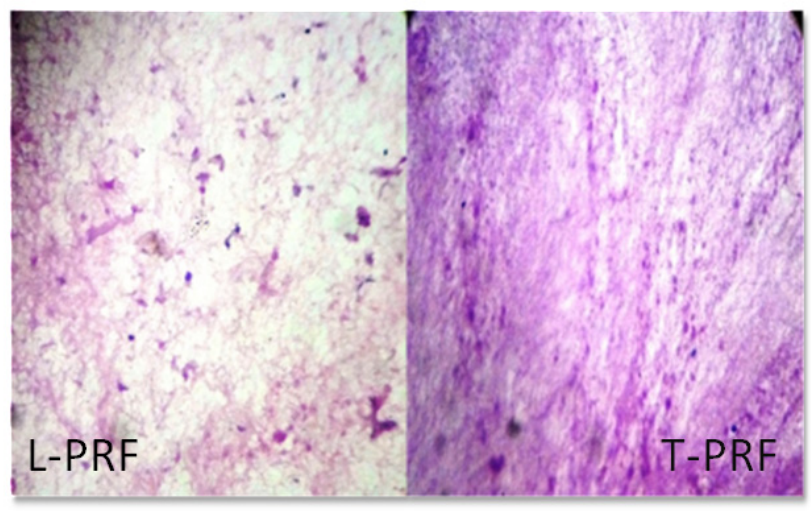

Figure 3: Histological analysis shows more number of fibroblasts and thicker fibrin structure in T-PRF when compared with L-PRF

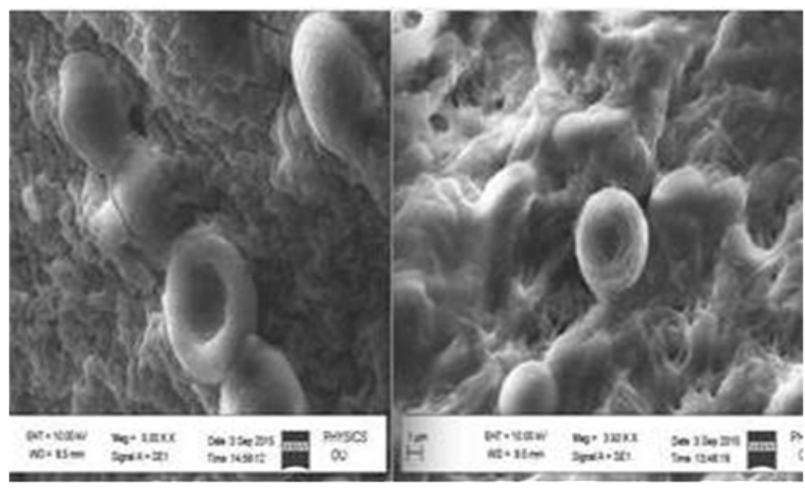

L-PRF

T-PRF

Figure 4: SEM analysis shows more woven and thicker fibrin structure in T-PRF when compared with L-PRF

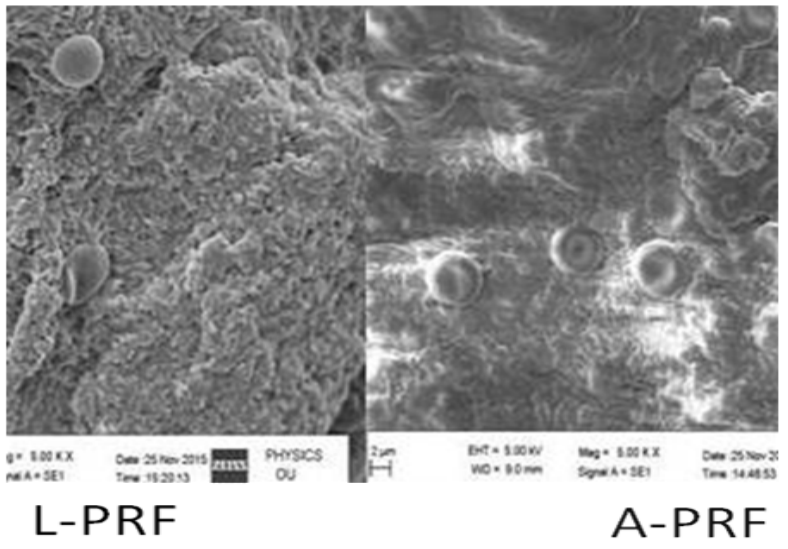

Figure 5: SEM analysis shows more a loose structure with more interfibrous space in A-PRF when compared with L-PRF

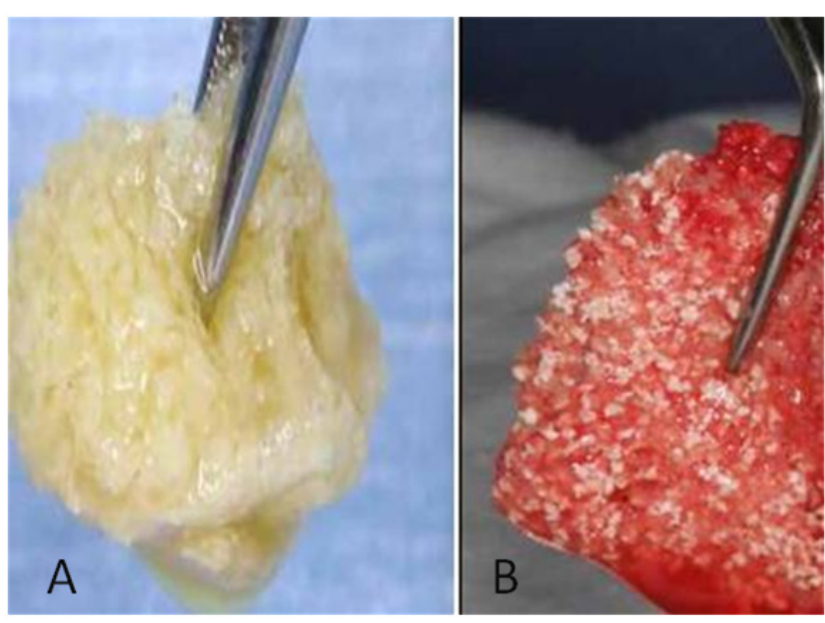

Figure 6: A) Mixing of AFG (Autologus fibrin glue) to allograft or to mixture of allograft and xenograft produces Yellow sticky bone; B) Addition of exudates from CGF (Concentrated growth factors) to the mixture of AFG and allograft or to the mixture of AFG and allograft and xenograft combination produces red color sticky bone formation 
PRF in terms of absorption time in body and clinical advantage over L-PRF.9

INJ ECT ABLE PRF (I-PRF): The centrifugation protocol of A-PRF is $700 \mathrm{rpm} \mathrm{3-4}$ mins, Differ from Standard PRF Which is $2700 \mathrm{rpm}$ 12 mins. Un coated tube uses for preparation of APRF and I-PRF. ${ }^{10}$

\section{RATIONALE BEHIND INVE NTION OF A-PRF:}

1. Monocytes releases higher concentration of growth factors.

2. Decreases centrifugation rpm and increased time gave enhanced neutrophil granulocytes in the distal part ( yellow color) of the clot

3. Neutrophil granulocytes increases differentiation of monocytes

This liquid PRF mix with allo graft results steaky bone which uses for augmentation procedures around implants.

CONCENTRATED GROWTH FACTORS (CGF): Unlike PRF using constant centrifugation (2700 rpm 12 mins) speed, CGF utilizes altered centrifugation speed (2400-2700 rpm $12 \mathrm{mins}$ ) to produce much larger, denser and richer fibrin matrix containing growth factors. ${ }^{11}$

STICKY BONE : The centrifugation protocol of Autologus fibrin glue (AFG) is 2400-2700 rpm 2 mins. Less centrifugation time leads to availability of more growth factors. Sohn et al. 2010 fabricatedgrowth factors en riched bone graft matrix and called it as Sticky bone. Mixing of AFG (Autologus fibrin glue) to allo graft or to mixture of allo graft and xenograft produces Yellow sticky bone (Figure 6A).Addition of exudates from CGF (Concentrated growth factors) to the above mixture produces red color sticky bone formation(Figure 6B). U ncoated tube uses for preparation of AFG. ${ }^{11}$

\section{Brief Summary on Centrifugation Protocol of Various PRF:}

\begin{tabular}{cl}
\hline Various PRF & Centrifuge protocols \\
\hline L-PRF & 2700 rpm 12 mins \\
\hline T-PRF & $2700 \mathrm{rpm} \mathrm{12}$ mins \\
\hline A-PRF & $\mathbf{1 5 0 0 ~ r p m ~ 1 4 ~ m i n s ~}$ \\
\hline I-PRF & $\mathbf{7 0 0 ~ r p m ~ 3 - 4 ~ m i n s ~}$ \\
\hline CGF & $\mathbf{2 4 0 0 - 2 7 0 0 r p m ~ 1 2 ~ m i n s}$ \\
\hline AFG & $\mathbf{2 4 0 0 - 2 7 0 0 ~ r p m ~} 2$ mins \\
\hline
\end{tabular}

\section{Conclusion:}

The use of PRF shows positive edge over conventional treatments in the process of regeneration of diseased tissue as they releasevarious polypeptide growth factors. Despite the evidence of clinical advantage of these preparations, evidence of their beneficial effects is still lacking. Hence there is a requirement for thejustification of their widespread use. Additional studies will be required for the determining the full effect of these preparations. They will be welcomed for use by the Periodontist, as long as they provide consistent benefit.

\section{References:}

1. Pradeep AR, Shetty SK, Garg G, Pai S. Clinical effectiveness of autologous platelet-rich plasma and peptide-enhanced bone graft in the treatment of intrabony defects. J Periodontol 2009; 80:62-71.

2. Sunitha Raja V, Munirathnam Naidu E. Platelet rich fibrin: evolution of a second generation platel et concentrate. Indian J Dent Res 2008; 19:42-46.

3. Dohan DM, Choukroun J, Diss A, Dohan SL, Dohan AJ Mouhyi J et al .Platelet-rich fibrin (PRF): a secondgeneration platelet concentrate. Part I: technological concepts and evolution. Oral Surg Oral Med Oral Pathol Oral Radiol Endod 2006; 101:37-44.

4. Dohan DM, Choukroun J, Diss A, Dohan SL, Dohan AJ , Mouhyil et al. Platelet-rich fibrin (PRF): a secondgeneration platelet concentrate. Part III: leucocyte activation: a new featurefor platel et concentrates? Oral Surg Oral Med Oral Pathol Oral Radiol Endod 2006; 101:51-55.

5. Choukroun J, Diss A, Simonpieri A, Girard MO, Schoeffler $C$, Dohan SL et al Platelet-rich fibrin (PRF): a secondgeneration platelet concentrate. Part IV: clinical effects on tissue healing. Oral Surg Oral Med Oral Pathol Oral Radiol Endod 2006; 101:56-60.

6. Tunal M, Ozdemir H, Kuçukodaci Z, Akman S, Yaprak E, and Firatl E. "I $n$ vivo evaluation of titanium-prepared platelet-rich fibrin (T-PRF): a new platelet concentrate". Br J Oral Maxillofac Surg 2012; 51(5):438-443.

7. Takemoto S, Yamamoto T, Tsuru K, Hayakawa S, Osaka, $\mathrm{A}$ and Takashima S. "Platelet adhesion on titanium oxide gels: effect of surface oxidation". Biomaterials 2004; 25(17):3485-3492.

8. M. Tunalý, H. Ozdemir, Z. Kuçukodaci, S. Akman, E. Yaprak, and E. Firatlý. A Novel Platelet Concentrate: Titanium-Prepared Platelet-Rich Fibrin. Biomed res inter 2014; 1; 1-7.

9. J oseph Choukroun et al. Advanced Platelet-rich fibrin: A new concept for cell based tissue engineering by means of inflammatory cells. J Oral I mplant 2014; 40:680-689.

10. J oseph Choukroun. Regenerative innovative therapies approaches: Advanced Platelet rich fibrin \& Inject able Platelet rich fibrin-Webinar.

11. Sohn et al. Utilization of Autologus concentrated growth factors (GGF) enriched bone graft matrix (Sticky bone) and CGF-Enriched membrane in implant dentistry. The J Implant Adv Clin Dent 2015; 7:11-27. 